\title{
Transmammary Route of Administration
}

National Cancer Institute

\section{Source}

National Cancer Institute. Transmammary Route of Administration. NCI Thesaurus.

Code C111326.

Administration into the body through colostrum or milk. 